\title{
Social Comparison Orientation and Perspective Taking as Related to Responses to a Victim
}

\author{
Abraham P. Buunk ${ }^{1,2}{ }^{2}$, Pieternel Dijkstra ${ }^{3}$ \\ ${ }^{1}$ Royal Netherlands Academy of Arts and Sciences, Groningen, The Netherlands \\ ${ }^{2}$ Sciences and University of Groningen, Groningen, The Netherlands \\ ${ }^{3}$ University of Groningen, Groningen, The Netherlands \\ Email: a.p.buunk@rug.nl
}

Received 22 January 2014; revised 23 February 2014; accepted 21 March 2014

Copyright (C) 2014 by authors and Scientific Research Publishing Inc.

This work is licensed under the Creative Commons Attribution International License (CC BY). http://creativecommons.org/licenses/by/4.0/

c) (i) Open Access

\section{Abstract}

The present study examined the effect of social comparison orientation (SCO) on the responses to a victim. Participants $(n=87)$ were exposed to an interview with the alleged victim of a traffic accident, that was either an unfamiliar or a close other. A close other induced more feelings of oneness and more personal distress, but not more empathy, than an unfamiliar other. Higher levels of SCO resulted in more feelings of oneness and more helping behavior only in response to an unfamiliar other. The results suggest that those high in SCO tend to perceive more identification with others they do not know than those low in SCO.

\section{Keywords}

Empathy, Distress, Helping, Social Comparison Orientation

\section{Introduction}

Comparing oneself with others seems a universal feature of the social life of humans. Nevertheless, in the past decades, it has been suggested by various authors that people may differ in their disposition to compare themselves with others. For instance, Diener and Fujita (1997) argued that “... making any comparisons at all, may often be a function of one's personality” (p. 349; see also Hemphill \& Lehman, 1991). Indeed, as put forward by Gibbons and Buunk (1999), there may be important individual differences in the extent to which, and the frequency with which people compare themselves with others. Gibbons and Buunk introduced the term social

${ }^{*}$ Corresponding author. 
comparison orientation (SCO) to refer to such individual differences. There is substantial evidence that those high in SCO seek out more comparisons, spend more time engaging in comparisons, and experience more emotional reactions from comparing themselves with others. SCO has been shown to affect a wide variety of outcomes, including for example one's personal risk perceptions, the perception of one's relational future, the development of occupational burnout and the quality of life of cancer patients (for a review, see Buunk \& Gibbons, 2006), and has more recently been related to such issues as openness to leadership behavior (van Quakebeke, van Knippenberg, \& Eckloff, 2011) and the discrepancy between the ideal and the ought self (McIntyre \& Eisenstadt, 2011).

In the present study we expanded the potential role of SCO to yet another domain, i.e., the responses to a victim as studied by Batson and his colleagues in their pioneering research (e.g., Batson, 1991; Batson, Fultz, \& Schoenrade, 1987). Batson and his colleagues made a distinction between personal distress and empathy as responses to a victim. Personal distress was defined as a self-focused negative emotional arousal in reaction to the perceived distress of another person, which involves feelings such as alarmed, upset, disturbed and distressed. Empathy was defined as an emotional response, elicited by and congruent with, but not necessarily identical to, the perceived welfare of someone else (Batson, 1991; Batson \& Oleson, 1991; Batson et al., 1995). According to the empathy-altruism model of Batson, especially feelings of empathy will result in helping behavior. Others have argued, however, that also feelings of personal distress may stimulate helping behavior. According to the negative state relief model (e.g., Cialdini \& Kenrick, 1976) individuals may help victims because helping the victim may reduce individuals negative affect, such as feelings of guilt, that is evoked by the victim's suffering (see also Cunningham, Steinberg, \& Grev, 1980). We expected individuals high in SCO to show relatively more personal distress and empathy in response to a victim - in the present research someone who was physically handicapped as a result of an accident-and, consequently, to show a higher tendency to help the victim. There were a number of arguments for this prediction. First, as shown by Mussweiler (2001, 2003), when comparing themselves with others, individuals look primarily for similarities between themselves and others, which suggests that individuals will detect more similarities between themselves and victims as they are higher in SCO. Second, individuals high in SCO tend to show relatively more congruent responses, i.e., negative affect, when confronted with someone who is worse-off than they are themselves. For example, a study among nurses Buunk, Van der Zee and Van Yperen (2001a) showed that the higher their SCO, the more negative affect nurses experienced in response to the description of a similar nurse who was doing poorly at work (see also Buunk, Ybema, Gibbons, \& Ipenburg, 2001b). Third, individuals high in SCO have a stronger interpersonal and communal orientation (Gibbons \& Buunk, 1999), i.e., tend to be more interested in what others experience and in caring for others in need (Swap \& Rubin, 1983; Clark, Ouellette, Powell, \& Milberg, 1987). Therefore, those high in SCO will, in general, view the fate of a victim as a situation that might happen to oneself, and will be emotionally relatively more affected by that fate, both in terms of empathy as well as personal distress.

We assumed, however, that the extent in which the responses to a victim will differ between those high and low in SCO will depend on the perspective one takes when considering the situation of that victim (Batson, 1991; Batson, Early, \& Salvarani, 1997). We included the commonly used “other" perspective in which participants are asked to imagine how the victim must perceive the situation, and consequently, which affect that situation will arouse in the victim. This perspective concerns basically another individual who is a stranger. Batson et al. (1997) showed that inducing this perspective leads to higher levels of empathy than inducing participants to try to stay objective and not to get involved in the suffering of the person in need (cf. Cialdini, \& Schaller et al., 1987). We compared this unfamiliar other perspective to what we refer to as the close other perspective, in which participants were asked to imagine that the situation of the victim occurred to someone who was close to them.

We expected that, overall, when they imagined a victim to be a close other, individuals would feel more closeness, empathy and distress, and, consequently, would be more likely to help. As it seems quite self-evident that individuals will in general experience more personal distress and empathy in response to someone who is close to them, we did not expect that SCO would make much difference in this respect. However, as there is increasing evidence that those high in SCO tend to perceive themselves to be more similar and close to unfamiliar others (Bosch et al., 2010; Buunk, Dijkstra, Bosch \& Siero, 2012; Michinov \& Michinov, 2001), we expected when confronted with an unfamiliar other, those high in SCO will experience more personal distress and empathy than those low in SCO and to be more inclined to help the victim.

Given our theoretical reasoning, we also examined directly to what extent SCO affected the psychological identification with the victim. Characteristic of a high level of psychological closeness is a strong identification 
with someone else as a person, a sense of overlapping selves, and a lack of differentiation between the self and the other, a condition labeled as closeness, of as inclusion of other in the self by Aron, Aron and Smollan (1992). In their research program, Aron and his colleagues developed the Inclusion of Other in the Self (IOS) Scale, a single-item, pictorial measure of closeness, demonstrated alternate-form and test-retest reliability; convergent validity scales assessing related constructs, such as marital satisfaction and commitment, discriminant validity; minimal social desirability, and predictive validity for whether romantic relationships were intact three months later, and for intimacy and attraction measures in stranger dyads following laboratory closeness-generating tasks. Most participants tended to interpret the IOS Scale diagrams as depicting interconnectedness. In line with Buunk et al. (2012), we expected that women high in SCO would, in general, perceive higher inclusion in the self of the victim, than women low in SCO, but specifically, or only when the victim was an unfamiliar other. This moderating role of SCO was not expected with respect to a close other as people would in general identify with someone who is close to them who is the victim of a serious accident.

Finally, we examined if perspective - taking the perspective of the close versus the unfamiliar other-and SCO affected actual helping behavior in the form of donating money, becoming a volunteer or becoming a collector for an existing Dutch organization dedicated to providing care to victims of, among others, accidents and crimes. In general, we expected women to be more inclined to help a close other than an unfamiliar other. As noted before, however, we would expect women high in SCO to be more willing to engage in helping behavior than women low in SCO, but particularly, after taking the perspective of an unfamiliar other.

\section{Method}

\subsection{Participants}

Eighty-seven female psychology students (mean age 21.02 years, $S D 1.60$ years, ranging from 18 to 26 years old) participated in exchange for the chance to win a DVD player.

\subsection{Procedure}

The participants were led to believe that the research was conducted to test an advertisement campaign for a well-known actually existing Dutch institution called Victim Care. The main focus of this institution was to provide psychological support to people who have been recently the victim of some sort of trauma. The participants were told that the results of this study would help Victim Care in determining how to conduct a follow-up national research. They also read an introduction about Leonie, a student who had a major bicycle accident and consequently ended up with serious facial damage, a shattered foot, and social stigma. Participants were told that Leonie would talk in an interview about her experiences. Before listening to the interview, the experimental manipulation was introduced to the participants following Batson et al. (1997).

Those assigned to the unfamiliar other condition read:

"Try, while listening to the interview, to imagine how the person being interviewed feels about what happened and how it has affected her life. Try not to concern yourself with attending to all the information presented. Just try to imagine how the person interviewed feels and concentrate on this.” The instruction stayed on the participants' screen while listening to the interview.

Those assigned to the close other condition read:

"Think of someone who is close to you, like a sibling or a good friend. Describe in four lines why that individual is important to you. Mention five characteristics of this person. Try, while listening to the interview, to imagine how the person you have just described would feel if he or she would experience what the person being interviewed is experiencing and how it would affect her life. Try not to concern yourself with attending to all the information presented. Just try to imagine how the person you have just described would feel and concentrate on this.

The instruction stayed on the screen while listening to the interview.

In the interview, Leonie told about her experiences in the hospital, how she felt when she saw herself again for the first time, how she has been recovering, and how she is feeling when people stare at her. She ended her story saying that she would like to meet some new people who would be willing to do something "nice" with her. Participants then completed a set of questionnaires (described below); upon completion, participants were fully 
debriefed and thanked for their participation.

\subsection{Measures}

Social Comparison Orientation. Before being exposed to the experimental manipulation, participants first filled out the 11-item scale for SCO developed by Gibbons and Buunk (1999) on the basis of a larger item pool. The scale has been tested in over 60 studies. The measure consists of statements reflecting social comparison activities and interests, including "I always like to know what others in a similar situation would do", "I always pay a lot of attention to how I do things compare with how others do things". The reversed items ("I am not the type of person who compares often with others" and "I never consider my situation in life relative to that of other people") were recoded. The items were measured on a 5-point scale, ranging from strongly disagree (1) to strongly agree (5). In the present sample, Cronbach's alpha $=.80, M=39.99, S D=6.33$.

As dependent variables the following measures were included.

Psychological closeness. To assess psychological closeness with the victim, we used the measure of closeness as assessed with the Inclusion of Others in Self Scale (IOS; Aron, Aron, \& Smollan, 1992), that has been extensively validated (Aron \& Fraley, 1999). The IOS exists of seven drawings of two gradually more overlapping circles. The IOS is a single-item, pictorial measure of interpersonal interconnectedness that consists of seven pictures of each two circles that overlap to different degrees, from no overlap (picture 1) to an almost complete overlap (picture 7).

Distress. In most of their studies, Batson and his colleagues have used eight items to assess distress, i.e., alarmed, grieved, troubled, distressed, upset, disturbed, worried and perturbed. By translation and back-translation, we tried to come up with as adequate as possible Dutch translations for the eight items. Participants provided responses on 7-point scales ranging from 1 (not at all) to 7 (very much). As usual, the scale had a very high reliability, alpha $=.89$, that could not be raised by deleting any item.

Empathy. In most of their studies, Batson and his colleagues have used six items to assess empathy, i.e., sympathetic, compassionate, softhearted, tender, warm and moved. Niezink et al. (2012) conducted factor analyses in 9 different samples (including the present one) on these adjectives. Across samples, a two factor solution distinguished between a "sympathy cluster" and a "tenderness cluster" of adjectives: whereas the adjectives compassionate, sympathetic, and moved had relatively high loadings on the first factor and relatively low loadings on the second factor, the opposite was found for the adjectives tender, warm, and softhearted. However, to make our results comparable to those used in similar research, we used the six original items commonly used in this paradigm. On 7-point scales, ranging from 1 (not at all) to 7 (very much), participants indicated the extent to which they felt these emotions. Despite the two factors that seem to underlie the scale, the scale had a high reliability, alpha $=.76$, that could not be raised by deleting any item.

Helping behavior. After asking participants a number of questions on their attitudes towards helping, to measure actual helping behavior, the questionnaire ended with a letter of authority. On this letter, participants could indicate whether they would support "Victim Care" by donating money, becoming a volunteer or becoming a collector for "Victim Care". The answers to these questions were dichotomized as "no" (1) or "yes" (2).

\section{Results}

Effects of Perspective. We expected that, overall, when they imagined a victim to be a close other, individuals would feel more closeness, empathy and distress, and would be more likely to help. We therefore first executed a number of ANOVA's with perspective- taking the perspective of the close versus the unfamiliar other-as an independent variable. These analyses showed significant differences between the two conditions for two of the three dependent variables, with stronger responses when taking the perspective of the close than when taking the perspective of the unfamiliar victim. The effect on distress was significant, $F(1,85)=6.69, p=.01$, with more distress expressed when taking the perspective of a close other, $M=4.45, S D=1.12$, than when taking the perspective of an unfamiliar other, $M=3.83, S D=1.10$. Although participants also expressed more empathy when taking the perspective of a close other, $M=4.81, S D=.83$, than when taking the perspective of an unfamiliar other, $M=4.54, S D=.76$, the difference was not significant, $F(1,85)=2.49, p=.12$. The effect on oneness was significant, $F(1,85)=5.13, p=.03$, with more closeness expressed when taking the perspective of a close other, $M=4.72, S D=1.34$, than when taking the perspective of an unfamiliar other, $M=4.07, S D=1.35$. Thus, participants experienced more closeness and distress, but not more empathy, when taking the perspective of a close other than when taking the perspective of an unfamiliar other. We next examined separately the effects of 
perspective on the sympathy and tenderness cluster that came out of the factor analytic studies by Niezink et al. (2012) on the empathy scale. The effects were even weaker than on the total scale, and neither effect was significant, respectively $F(1,85)=1.07, p=.30$, and $F(1,85)=2.11, p=.15$

Effects of SCO. To examine the main issue in this study, i.e., the moderating role of SCO, we did a series of GLM analyses with perspective and the centered SCO as predictors, including the interaction between both variables. Unlike what we expected, there were no main or interaction effects of SCO on empathy and distress, $F$ 's $<1.25$, $p$ 's $>.27$. While the main effect of SCO on closeness was not significant, $F(1,83)=.10, p=.76$, there was, in addition to the main effect of perspective, $F(1,83)=11.74, p=.00$, a significant interaction between SCO and perspective, $F(1,83)=9.63, p=.00$. Figure 1 shows that although individuals taking the perspective of a close other experienced, on average, more closeness than individuals taking the perspective of an unfamiliar other, this effect was dependent on levels of SCO. More specifically, SCO appeared to have opposite effects on closeness in the two conditions. When taking the perspective of a close other, those high in SCO experienced somewhat less closeness with the victim than those low in SCO, $\beta=-.27$, an effect that was only marginally significant, $p=.08$. However, when imagining that the victim was an unfamiliar other, those high in SCO experienced more closeness with the victim than those low in SCO, $\beta=.38, p=.01$.

Helping behavior. After the experiment, $45 \%$ of the participants donated money for Victim Care, although only $11 \%$ signed up to collect money for Victim Care, and even fewer participants (6\%) signed up to do volunteer work. Given the very low base rates of these last two behaviors, the results of presented here should be viewed with caution, but we nevertheless report these to be comparable with the analyses for the other dependent variables. As the dependent variables were dichotomous, we did logistic regressions, with the scores for SCO centered. We report here the significance of the B's in the final models. These analyses showed no main or interaction effects of perspective and SCO neither on donating money for Victim Care, nor on signing up for volunteer work, $p$ 's $>.19$. However, while the effect of perspective on signing up to collect money for Victim Care was not significant, $\mathrm{B}=.49(\mathrm{SE}=.85), p=.56$, the effect of SCO was significant, $\mathrm{B}=.65(\mathrm{SE}=.31), p$ $=.03$, as was the interaction between perspective and SCO, $\mathrm{B}=-.25(\mathrm{SE}=.12), p=.03$. Given the fact that only a few people in both conditions signed up to collect money, we did a series of tests to examine the data more closely. First, a Chi ${ }^{2}$ test showed that there was no difference between both conditions in the number of people that signed up to collect money, $C h i^{2}(1,83)=.15, p=.48$, confirming the main effect found in the regression. Second, the range of scores on SCO for those who signed up was in the close other condition 30 to 46 , and in the unfamiliar other condition 32 to 53. All these scores fell within the range of 2 SD's below and above the scale mean (respectively, 27 and 53), suggesting that outliers could not be responsible for the effects of SCO on signing up to collect money. Third, we did ANOVA's in both conditions to examine the association between this signing up and SCO. Given the low $n$ 's, we adopted a significance level of $10 \%$, in accordance with the suggestion of Cohen. We did not find a significant association with SCO for those who took the perspective of a close other, $F(1,39)=1.66, p=.21$, but did find a significant association with SCO for those who took the perspective of an unfamiliar other, $F(1,40)=3.55, p=.07$. To model these effects in the same way as for closeness, regression lines were drawn. As Figure 2 shows, when taking the perspective of a close other, those higher in SCO signed up less often, albeit not significantly less, to collect money for Victim Care than those low in SCO, $\beta=-.20, p=.21$. In contrast, when imagining that the victim was an unfamiliar other, those high in SCO signed up more often to collect money for Victim Care than those low in SCO, $\beta=.29, p=.07$. In other words, as illustrated in Figure 2, even with the very low base rate of signing up, our findings suggest that those high in SCO signed up to collect money more often when the victim was an unfamiliar other than when she was imagined as a close other.

Because the effects of SCO for closeness and signing up to collect money were rather similar, we considered the possibility that closeness might in both conditions mediate between SCO and helping behavior. That would require that, in addition to the effects of SCO on both variables, closeness also correlated with helping behavior. However, that appeared not to be the case, in the unfamiliar other condition $r=.17, p=.27$, nor in the close other condition $r=-.04, p=.82$. Thus, the effects of SCO on closeness and helping behavior seem to be independent of one another. As SCO did not have any effects on empathy and personal distress, these latter variables could not mediate between SCO and helping behavior.

\section{Discussion}

We examined the role of social comparison orientation (SCO) and different perspectives in affecting the res- 


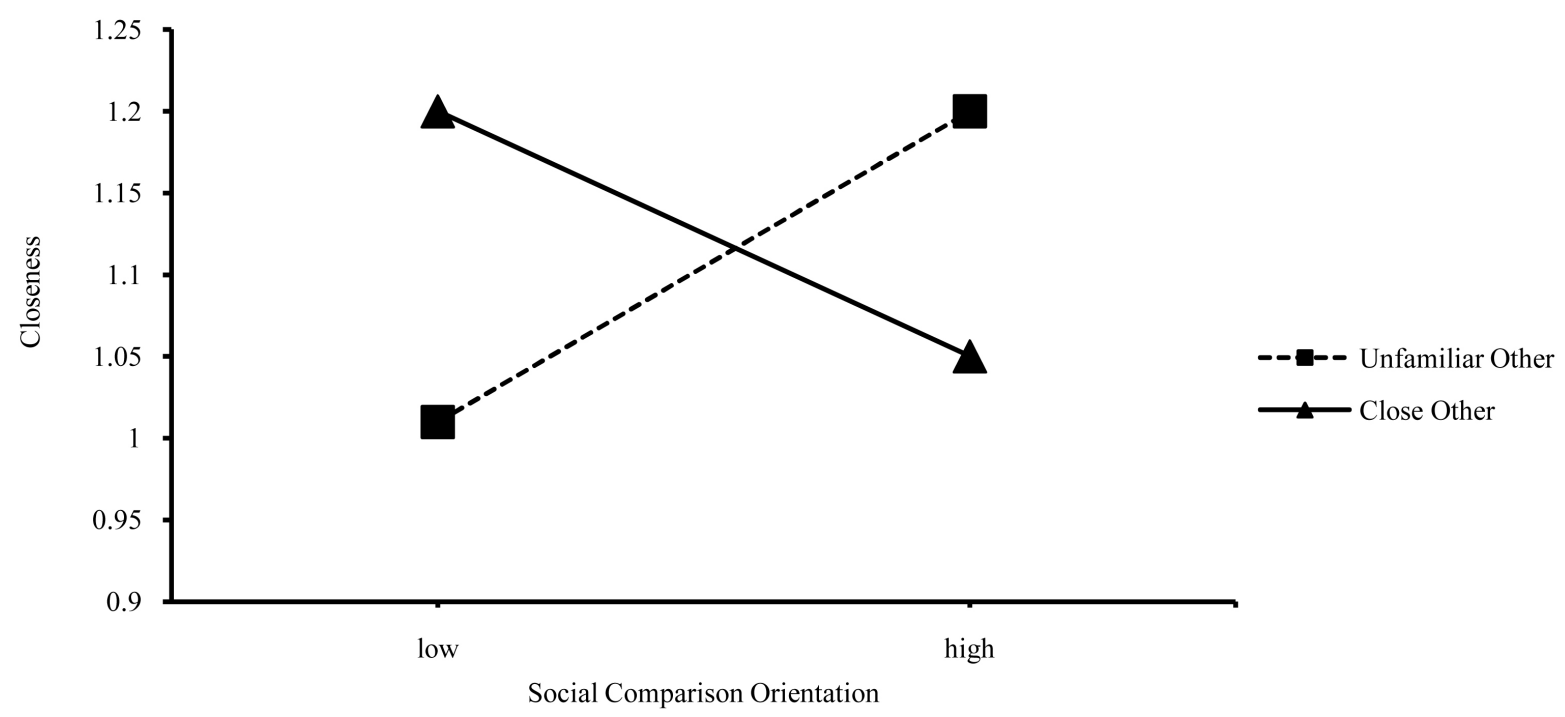

Figure 1. Effects of SCO on feelings of closeness after imagining the victim as either an unfamiliar or close other.

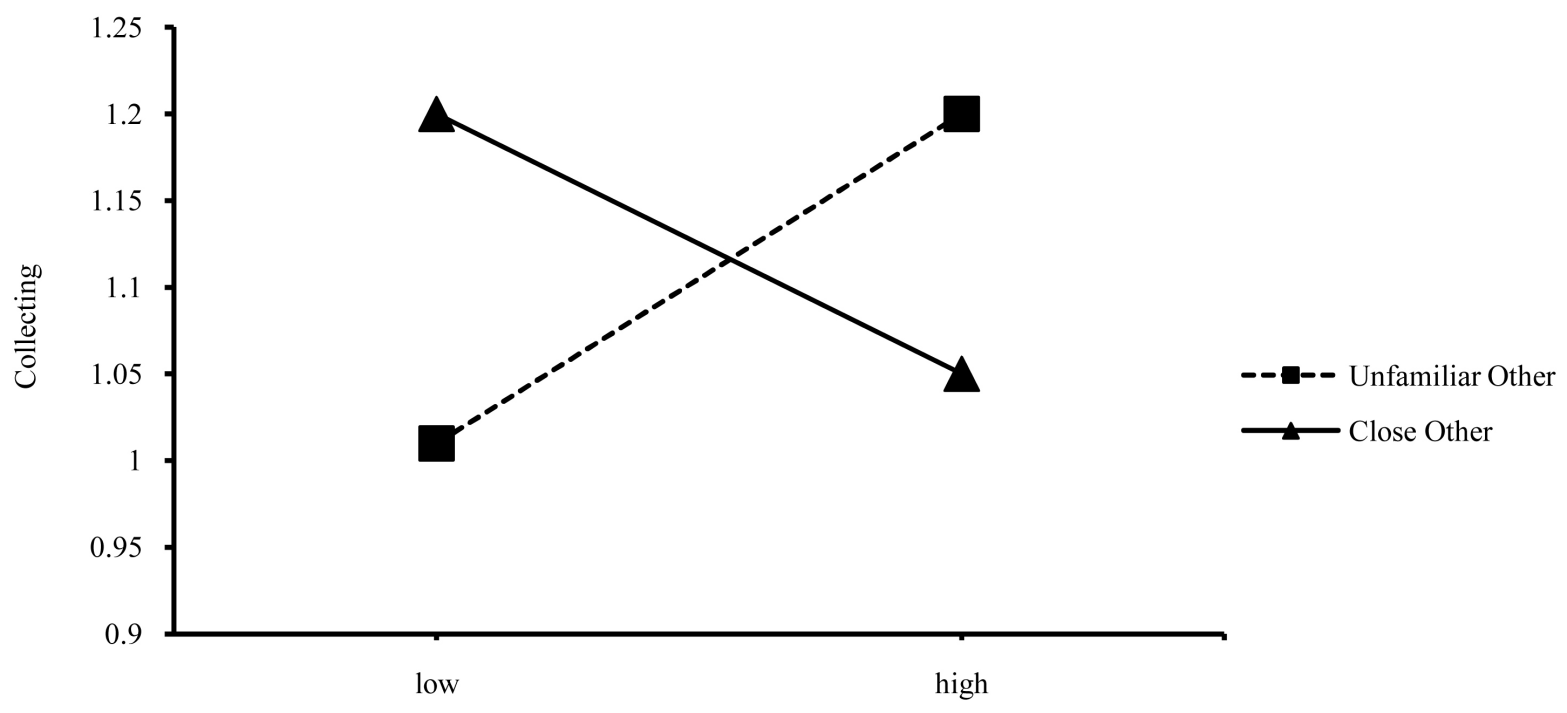

Social Comparison Orientation

Figure 2. Effects of SCO on signing up to collect for Victim Care after imagining the victim as either an unfamiliar or close other.

ponses of women to an interview with the alleged victim of a traffic accident. We induced two perspectives: an unfamiliar other perspective condition in which the victim was described in general terms, and a close other perspective condition in which participants were asked to imagine that the victim was someone close to them. We expected that, overall, when they imagined a victim to be a close other, individuals would feel more closeness, empathy and distress, and would be more likely to help. Indeed, we found partial evidence for this idea. Taking the perspective of a close other resulted indeed in more feelings of closeness with the victim and in more personal distress, but not in more empathy with the victim, than taking the perspective of an unfamiliar other. This last finding is quite interesting, as it underlines, in line with the work by Batson and his colleagues (e.g., Batson et al., 1987), that empathy and personal distress are quite distinct responses to a confrontation with a victim. That is, as research in neuroscience suggests (Keysers, 2011), empathy seems a rather general response that may be evoked by the suffering of any other individual, independent of how close that other person is. Indeed, we may feel empathy for victims of famine, war or disasters, from any part of the world. However, being 
touched by the fate of victims we do not know personally, does not necessarily mean that we also experience personal distress, that is, that we feel worried, concerned or upset. Our present findings suggest that such responses only, or particularly, occur when we are confronted with a close other who is the victim of an accident, whereas the level of empathy in such a case is similar to that experienced in response to victims who are complete strangers. However, our findings suggest that the effect of perspective taking on helping behavior is not parallel to that on the affect evoked by imaging that the victim was a close or an unfamiliar. A practical implication of this finding would be that, when trying to collect money for an organization that aims to help victims of a particular event, inducing women to imagine that someone who is close to them might be the victim of such an event, might not be a more effective strategy than simply presenting women with the same fate of unknown others, and asking women to think about how such people might feel. Moreover, in individuals low in pro-social motivation, when the costs of helping are high, efforts to induce empathy situationally can even undermine pro-social behavior (Graziano et al., 2007): these individuals may perceive the empathic request for help as too burdensome and completely refrain from helping.

The major focus of the present research was to what extent SCO might affect the responses to a victim. In line with other recent studies (Bosch et al., 2010; Buunk et al., 2012), we expected that SCO would particularly affect the responses to an unfamiliar other. We found clear support for our hypotheses with respect to closeness. SCO resulted in more closeness when taking the perspective of an unfamiliar other, but in less closeness when taking the perspective of a close other. In fact, whereas those low in SCO experienced more closeness with a close than with an unfamiliar other, those high in SCO experienced as much closeness with an unfamiliar as with a close other. These results seem in line with the interpretation that those high in SCO tend in general to perceive the fate of others as their own possible fate and tend to try to recognize themselves in others, and that, as Mussweiler $(2001,2003)$ has demonstrated, social comparison implies primarily searching for similarities between oneself and the comparison target. The present findings are also compatible with the results from the study by Michinov and Michinov (2001), who found that individuals high in SCO felt attracted to individuals regardless of whether they were similar in their attitudes and opinions or not. In contrast, individuals low in SCO felt attracted only to others who were similar in their attitudes and opinions, i.e., others who were more likely viewed as psychologically closer. Thus, in general, those high in SCO tend to experience themselves as similar to others regardless of whether the other is a close other or not, whereas those low in SCO tend to clearly discriminate between close and non-close others. However, we did not find any evidence that these differences between those high and low in SCO extended to empathy and personal distress. This suggests that previous findings showing more negative affect among those high in SCO in response to others worse off, may not, as often has been suggested, be explained as indications of empathy and personal distress (e.g., Buunk et al., 2001a, 2001b).

Despite the fact that women high in SCO did not experience more empathy and personal distress, we found some preliminary evidence that they were more likely to help unfamiliar victims. When the victim was an unfamiliar other, those high in SCO signed up somewhat more often to collect money for Victim Care than those low in SCO, and more often when the victim was an unfamiliar other than when she was imagined as a close other. Apparently, the inclination of women high in SCO to help, does not seem to be related to the extent to which they felt emotionally affected by the victim's fate. A reason that women high in SCO nonetheless may be more willing to help an unfamiliar other is revealed by an experiment by Graziano et al. (2007). In this highly similar experiment, in which participants were also presented with an audiotaped interview with a victim that was relatively familiar of unfamiliar to them, and requested to help in terms of hours volunteer work, Graziano et al. (2007)_studied the role of agreeableness in helping behavior. Very similar to what the present study found for individuals high in SCO, Graziano and colleagues found that participants high in agreeableness offered more help to relatively unfamiliar victims than to a relatively familiar one. Although agreeableness and SCO are usually found to be only weakly related (see for instance Buunk, Nauta, \& Molleman, 2005), individuals high in agreeableness and high in SCO, compared to other individuals, seem to have in common that they, in general, are more likely to perceive other people to be emotionally related or similar to themselves. Whereas individuals high in SCO may feel more connected to people in general, because they tend to focus on similarities between themselves and others, individuals high in agreeableness may feel so because they are, by nature, high in empathy (Graziano et al., 2007). Our finding that, under certain conditions, women high in SCO may be more likely to help is also consistent with studies that have shown cues that trigger social comparisons may enhance the likelihood of individuals engaging in pro-social behavior. For example, Shipley (2008) found that a social compari- 
son cue significantly increased the likelihood of donation. In a similar vein, Klein (2003) showed that individuals who received comparative feedback on their task performance, were more likely to give helpful hints to other participants on a subsequent task.

Nonetheless, the effect of SCO on helping behavior should be viewed as very preliminary for two reasons. First, this effect was only found for signing up to collect money for an organization devoted to helping victims, and not for actually donating money or signing up to do volunteer work. Second, the total number of people who signed up was very low. Our findings nevertheless seem interesting given the ongoing debate whether helping is always motivated by an altruistic tendency or may also be instigated by egocentric motives (Batson, 1991). The present research suggests that what might seem a rather ego-focused characteristic, that is, the dispositional tendency to compare oneself with others, may result in actual altruistic behavior. Our finding fits with the notion that although motivations for helping might appear altruistic, those motivations may be ultimately egoistic in nature, as they are mainly directed at close others (Maner et al., 2002; Cialdini et al., 1997). That is, if indeed individuals high in SCO define "close others" more broadly than others do, their helping behavior with regard to unfamiliar people makes perfect sense: these unfamiliar people are not really unfamiliar and are probably not too different from those in the category "close others". While we did not intend with the current research to tap into the debate over the existence of "true" altruism, we have found some preliminary evidence that individuals high in SCO have, more than individuals low in SCO, a "natural" inclination to feel psychologically close to victims they do not know personally and even to provide some type of help to such others.

The present research has a number of potential limitations. First, our measures of psychological closeness consisted of one item only. In general, including multiple items to assess a variable, contributes to the reliability of the measurement. However, we would like to note that the item we used for assessing psychological closeness, the IOS, has been thoroughly examined and validated (Aron \& Fraley, 1999). A second limitation is that we found only an effect of SCO on one of our three measures of helping behavior, i.e., signing up to collect money for Victim Care, and that only about $10 \%$ of the sample did do so. A third limitation is that the study was restricted to women, who may in general perceive more closeness with others than men. Finally, our findings may have limited generalizability in terms of gender and age and apply to young women only. Nevertheless, given the importance of social comparisons, we feel that our research makes a relevant contribution by refining and expanding our knowledge on characteristics of those high in SCO, and on the role of individual differences in SCO for altruism and helping behavior.

\section{Acknowledgements}

The authors thank Lidewij Niezink for her work in the design and running of the experiment, and Frans Siero for his methodological and editorial support.

\section{References}

Aron, A., \& Fraley, B. (1999). Relationship Closeness as Including Other in the Self: Cognitive Underpinnings and Measures. Social Cognition, 17, 140-160. http://dx.doi.org/10.1521/soco.1999.17.2.140

Aron, A., Aron, E. N., \& Smollan, D. (1992). Inclusion of Other in the Self Scale and the Structure of Interpersonal Closeness. Journal of Personality and Social Psychology, 63, 596-612. http://dx.doi.org/10.1037/0022-3514.63.4.596

Batson, C. D. (1991). The Altruism Question: Toward a Social-Psychological Answer. Hillsdale, NJ: Erlbaum.

Batson, C. D., \& Oleson, K. C. (1991). Current Status of the Empathy-Altruism Hypothesis. In M. S. Clark (Ed.), Prosocial Behavior: Review of Personality and Social Psychology (pp. 62-85). Newbury Park, CA: Sage.

Batson, C. D., Batson, J. G., Todd, M. R., Brummett, B. H., Shaw, L. L., \& Aldeguer, C. M. R. (1995). Empathy and the Collective Good: Caring for One of the Others in a Social Dilemma. Journal of Personality and Social Psychology, 68, 619-631. http://dx.doi.org/10.1037/0022-3514.68.4.619

Batson, C. D., Early, S., \& Salvarani, G. (1997). Perspective Taking: Imagining How Another Feels versus Imagining How You Would Feel. Personality and Social Psychology Bulletin, 23, 751-758. http://dx.doi.org/10.1177/0146167297237008

Batson, C. D., Fultz, J., \& Schoenrade, P. A. (1987). Distress and Empathy: Two Qualitatively Distinct Vicarious Emotions with Different Motivational Consequences. Journal of Personality, 55, 19-39.

http://dx.doi.org/10.1111/j.1467-6494.1987.tb00426.x

Bosch, A. Z., Buunk, A. P., Siero, F. W., \& Park, J. H. (2010). Why Some Women Can Feel More, and Others Less, Attractive after Exposure to Attractive Targets: The Role of Social Comparison Orientation. European Journal of Social 
Psychology, 40, 847-855.

Buunk, A. P., \& Gibbons, F. X. (2006). Social Comparison Orientation: A New Perspective on Those Who Do and Those Who Don’t Compare with Others. In S. Guimond (Ed.), Social Comparison and Social Psychology: Understanding Cognition, Intergroup, Relationship, and Culture (pp. 15-32). New York: Cambridge University Press.

Buunk, A. P., Dijkstra, P., Bosch, Z. A., Dijkstra, A., \& Barelds, D. P. (2012). Social Comparison Orientation as Related to Two Types of Closeness. Journal of Research in Personality, 46, 279-285. http://dx.doi.org/10.1016/j.jrp.2012.02.008

Buunk, A. P., Nauta, A., \& Molleman, E. (2005). In Search of the True Group Animal: The Effects of Affiliation Orientation and Social Comparison Orientation upon Group Satisfaction. European Journal of Personality, 19, 69-81. http://dx.doi.org/10.1002/per.532

Buunk, A. P., Van der Zee, K., \& VanYperen, N. W. (2001a). Neuroticism and Social Comparison Orientation as Moderators of Affective Responses to Social Comparison at Work. Journal of Personality, 69, 745-763. http://dx.doi.org/10.1111/1467-6494.695162

Buunk, A. P., Ybema, J. F., Gibbons, F. X., \& Ipenburg, M. (2001b). The Affective Consequences of Social Comparison as Related to Professional Burnout Andsocial Comparison Orientation. European Journal of Social Psychology, 31, $337-351$. http://dx.doi.org/10.1002/ejsp.41

Cialdini, R. B., Brown, S. L., Lewis, B. P., Luce, C., \& Neuberg, S. L. (1997). Reinterpreting the Empathy-Altruism Relationship: When One into One Equals Oneness. Journal of Personality and Social Psychology, 73, 481-494. http://dx.doi.org/10.1037/0022-3514.73.3.481

Cialdini, R. B., Schaller, M., Houlihan, D., Arps, K., Fultz, J., \& Beaman, A. L. (1987). Empathy-Based Helping: Is It Selflessly or Selfishly Motivated? Journal of Personality and Social Psychology, 52, 749-758. http://dx.doi.org/10.1037/0022-3514.52.4.749

Cialdini, R. B., \& Kenrick, D. T. (1976). Altruism as Hedonism: A Social Development Perspective on the Relationship of Negative Mood State and Helping. Journal of Personality and Social Psychology, 34, 907-914. http://dx.doi.org/10.1037/0022-3514.34.5.907

Clark, M. S., Ouellette, R., Powell, M. C., \& Milberg, S. (1987). Recipient’s Mood, Relationship Type, and Helping. Journal of Personality and Social Psychology, 53, 94-103. http://dx.doi.org/10.1037/0022-3514.53.1.94

Cunningham, M. R., Steinberg, J., \& Grev, R. (1980). Wanting to and Having to Help: Separate Motivations for Positive Mood and Guilt-Induced Helping. Journal of Personality and Social Psychology, 38, 181-192. http://dx.doi.org/10.1037/0022-3514.38.2.181

Diener, E., \& Fujita, F. (1997). Social Comparison and Subjective Well-Being. In B. P. Buunk, \& F. X. Gibbons, (Eds.), Health, Coping, and Well-Being: Perspectives from Social Comparison Theory (pp. 329-358). Mahwah, NJ: Erlbaum.

Gibbons, F. X., \& Buunk, B. P. (1999). Individual Differences in Social Comparison: Development of a Scale of Social Comparison Orientation. Journal of Personality and Social Psychology, 76, 129-142. http://dx.doi.org/10.1037/0022-3514.76.1.129

Graziano, W. G., Habashi, M. M., Sheese, B. E., \& Tobin, R. M. (2007). Agreeableness, Empathy, and Helping: A Person $\times$ Situation Perspective. Journal of Personality and Social Psychology, 93, 583-599. http://dx.doi.org/10.1037/0022-3514.93.4.583

Hemphill, K. J., \& Lehman, D. R. (1991). Social Comparisons and Their Affective Consequences: The Importance of Comparison Dimension and Individual Difference Variables. Journal of Social and Clinical Psychology, 10, 372-394. http://dx.doi.org/10.1521/jscp.1991.10.4.372

Keysers, C. (2011). The Empathic Brain. Chicago: University of Chicago Press.

Klein, W. P. (2003). Effects of Objective Feedback and “Single Other” or “Average Other” Social Comparison Feedback on Performance Judgments and Helping Behavior. Personality and Social Psychology Bulletin, 29, 418-429. http://dx.doi.org/10.1177/0146167203251195

Maner, J. K., Luce, C. L., Neuberg, S. L., Cialdini, R. B., Brown, S., \& Sagarin, B. J. (2002). The Effects of Perspective Taking on Motivations for Helping: Still No Evidence for Altruism. Personality and Social Psychology Bulletin, 28, 1601-1610. http://dx.doi.org/10.1177/014616702237586

Michinov, E., \& Michinov, N. (2001). The Similarity Hypothesis: A Test of the Moderating Role of Social Comparison Orientation. European Journal of Social Psychology, 31, 549-555. http://dx.doi.org/10.1002/ejsp.78

Mussweiler, T. (2001). Focus of Comparison as a Determinant of Assimilation versus Contrast in Social Comparison. Personality and Social Psychology Bulletin, 27, 38-47http://dx.doi.org/10.1177/0146167201271004

Mussweiler, T. (2003). Comparison Processes in Social Judgment: Mechanisms and Consequences. Psychological Review, 110, 472-489. http://dx.doi.org/10.1037/0033-295X.110.3.472

Niezink, L. W., Siero, F. W., Dijkstra, P., Buunk, A. P., \&Barelds, D. P. H. (2012). Empathic Concern: Distinguishing be- 
tween Tenderness and Sympathy. Motivation and Emotion, 36, 544-549. http://dx.doi.org/10.1007/s11031-011-9276-z

Shipley, A. (2008). Social Comparison and Prosocial Behavior: An Applied Study of Social Identity Theory in Community Food Drives. Psychological Reports, 102, 425-434. http://dx.doi.org/10.1007/s11031-011-9276-z

Swap, W. C., \& Rubin, J. Z. (1983). Measurement of Interpersonal Orientation. Journal of Personality and Social Psychology, 44, 208-219. http://dx.doi.org/10.1037/0022-3514.44.1.208 